\title{
La forma urbana como herramienta interpretativa de vulnerabilidad espacio-cultural. Caso de estudio: Mercado "El Tepetate"
}

\author{
María Teresa Trejo Guzmán \\ Departamento de Ciencias de la Tierra, \\ Tecnológico Nacional de México, Campus Querétaro, Querétaro, México \\ E-mail: arq_tere@mail.itq.edu.mx
}

\begin{abstract}
Resumen. Es innegable la decisiva influencia que el crecimiento de la ciudad tiene sobre la accesibilidad configuracional de la ciudad histórica preexistente. El territorio de la "Otra Banda", en la ciudad de Querétaro, México, como resultado de una cultura híbrida, tiene improntas profundas que denotan hasta hoy día, desigualdades estructurales. Se presenta un método de análisis de la forma urbana como herramienta interpretativa apoyada en la superposición de mapas históricos, la consideración de la teoría de Space Syntax y el software de análisis espacial multiplataforma DepthmapX, buscando los niveles de conectividad en esta parte de la ciudad. La identidad del lugar y su comercio efervescente, instan a visualizar que, como un elemento regulador, la rehabilitación del mercado "El Tepetate", puede contribuir a minimizar la vulnerabilidad del lugar. La morfología urbana muestra que, el sistema de accesibilidad evoluciona al tiempo que la ciudad crece y los niveles de integración de sus elementos permanecen o se modifican. La identificación de tendencias evidencia el continuo desconocimiento de las dinámicas históricas. El estudio muestra criterios de análisis que, coadyuvarian a la incorporación de estudios morfológicos históricos en la toma de decisiones urbanisticas. La memoria implica no olvidar, ser fiel al pasado es algo con lo que el ser humano cuenta para expresar y significar que «algo» ha acaecido.
\end{abstract}

Palabras clave: Barrios, exclusión, tradición, cartografia

\section{Introducción}

La 'intemporalidad' de las configuraciones espaciales en la ciudad, viene a dar soporte a los estudios que, en cuanto a forma urbana, se manifiestan en el presente documento, empleando la superposición de planos históricos y, el software de análisis espacial multiplataforma DepthmapX. Si bien al estudiar la morfología urbana, se esperaría que el sistema de accesibilidad evolucione al tiempo que la ciudad crece, también es posible que los niveles de integración de sus elementos puedan modificarse o permanecer. Ya estudiosos de la arquitectura fundamentan sus trabajos en análisis históricos abordando a la ciudad desde una perspectiva morfológica, Choay (2007) refiere de Camillo Sitte que "la ciudad antigua todavía puede darnos lecciones" (p. 168).

El mercado "El Tepetate" (el de mayor tradición en la ciudad), implica el desarrollo de actividades simultáneas: diariamente el mercado como espacio arquitectónico, en días específicos como mercado abierto "tianguis" el cual, había estado sucediéndose, hasta antes del incendio ocurrido el día 10 de agosto de 2018, en la explanada exterior inmediata al edificio, prolongándose hacia calles y locales aledaños a éste. El mercado y su entorno urbano, denotan escasa calidad urbano-arquitectónica, dificultad de acceso a la zona y problemas de orden social. 


\section{Antecedentes}

Desde la llegada del conquistador, en la ciudad de Querétaro, México, las bandas del otrora caudaloso río que atraviesa la ciudad, han fungido como elementos de diferenciación. De una banda, la nueva ciudad colonial con su traza en damero, en la otra banda, una parte de la ciudad de traza irregular dejada a los naturales. Es a partir de 1602 con las congregaciones de indios, donde surgen los "Barrios de la Otra Banda", lugar de ubicación del caso de estudio. Es claro que en los anteriores cinco renglones se encierra un «cronotopo» (liga al tiempo con el espacio y a los tiempos entre sí) histórico-territorial importante para la ciudad que presenta improntas profundas.

Querétaro es ejemplo de hibridación cultural resultado de la conquista. La ciudad vivió épocas de esplendor entre los siglos XVII y XVIII heredando monumentos, casonas, templos, palacios y un majestuoso acueducto, llegando a ser llamada por la hoy España en el siglo XVII como "La Perla del Bajío" y considerada como la "tercera ciudad del Reino". Tiempo y lugar conforman un esplendoroso cronotopo en construcción.

En años recientes, la ciudad de Querétaro ha mostrado intención de transformación logrando, entre varias de sus búsquedas la fortaleza económica. Recientemente, la ciudad ha iniciado a replantearse, como oportunidad de desarrollo, el turismo y el diseño de estrategias de marca-ciudad.

\section{De la historia como valor en la interpretación del presente.}

Lourdes Somohano (2006), plantea que en la época prehispánica Querétaro era pluriétnico, que fué un asentamiento cuyo nombre era Tlachco en náhuatl y Querétaro en purépecha, en ambas lenguas significa 'cancha de pelota'. En el asentamiento prehispánico de Tlachco, habitaban para 1536 circa, chichimecas y otomíes, ya en el Cerro de San Gremal había caseríos de manera dispersa en donde convivían dichos grupos, existiendo en ese lugar una plaza en donde se colocaba un tianguis. El pueblo de Tlachco se repobló con naturales vecinos del lugar mexicas, otomíes y chichimecas. Para
1541, Tlachco promueve el arribo de nuevos pobladores: tarascos, otomíes y mexicas. Luego con la conquista, la re-fundación de Santiago de Querétaro incrementa la plurietnicidad. El motor del continuo repoblamiento en la Nueva España tuvo que ver con las epidemias, la congregación de naturales dispersos, la necesidad de mano de obra para construir ciudades, el reparto de tierras y la conversión al catolicismo.

Para 1590 Somohano (2006) refiere de la distribución poblacional en Querétaro: "La parte de los mexicanos, en el norte de la nueva traza. [...] es la parte sur a donde biben los negros", (p. 251). En el "Mapa 1", se muestra, por superposición de planos, la ubicación de los primeros barrios en el pueblo de Querétaro apoyándose un mapa del año 1796.

Con la nueva campaña poblacional en el pueblo de Querétaro, entre 1602 y 1603, llegan nuevos habitantes al lugar: "El reacomodo de hizo en cuatro congregaciones situadas en los márgenes de Querétaro, con pobladores provenientes de todos los pueblos vecinos, [...]" (Somohano, L. 2006, p. 256). En la "Figura 1" se aprecia la pintura presentada por Hernán Sánchez Cortés, en 1620 a la Corona de Castilla: se indican las 4 Congregaciones ocurridas en la tercera reducción de nativos en el pueblo de Querétaro entre 1602 y 1603: La Cañada, El Rincón, Santa María y San Roque (zona de estudio).

Querétaro fué, paso obligado en la ruta del Camino Real de Tierra Adentro hacia el norte de la entonces Nueva España. El camino fue razón de la búsqueda de zonas argentíferas lo que, detonó gran dinamismo en el centro de México, justo en el Bajío y en Querétaro, convirtiéndose la ciudad en un centro de enorme auge económico cuya consecuencia, se atreve a denominar quien escribe, resultó en "una primera gentrificación". En la década de 1760, la zona del Bajío (y Querétaro) se desempeñaba como la más rica de la naciente América, las vocaciones territoriales de sus ciudades: minera, comercial, textil y de hacienda agrícola, dieron impulso de manera acelerada hacia una economía capitalista lo cual, conllevó a su vez desigualdad, pobreza, inseguridad e inequidad a las familias trabajadoras. La Nueva España entró en caos cuando, a principios del siglo 


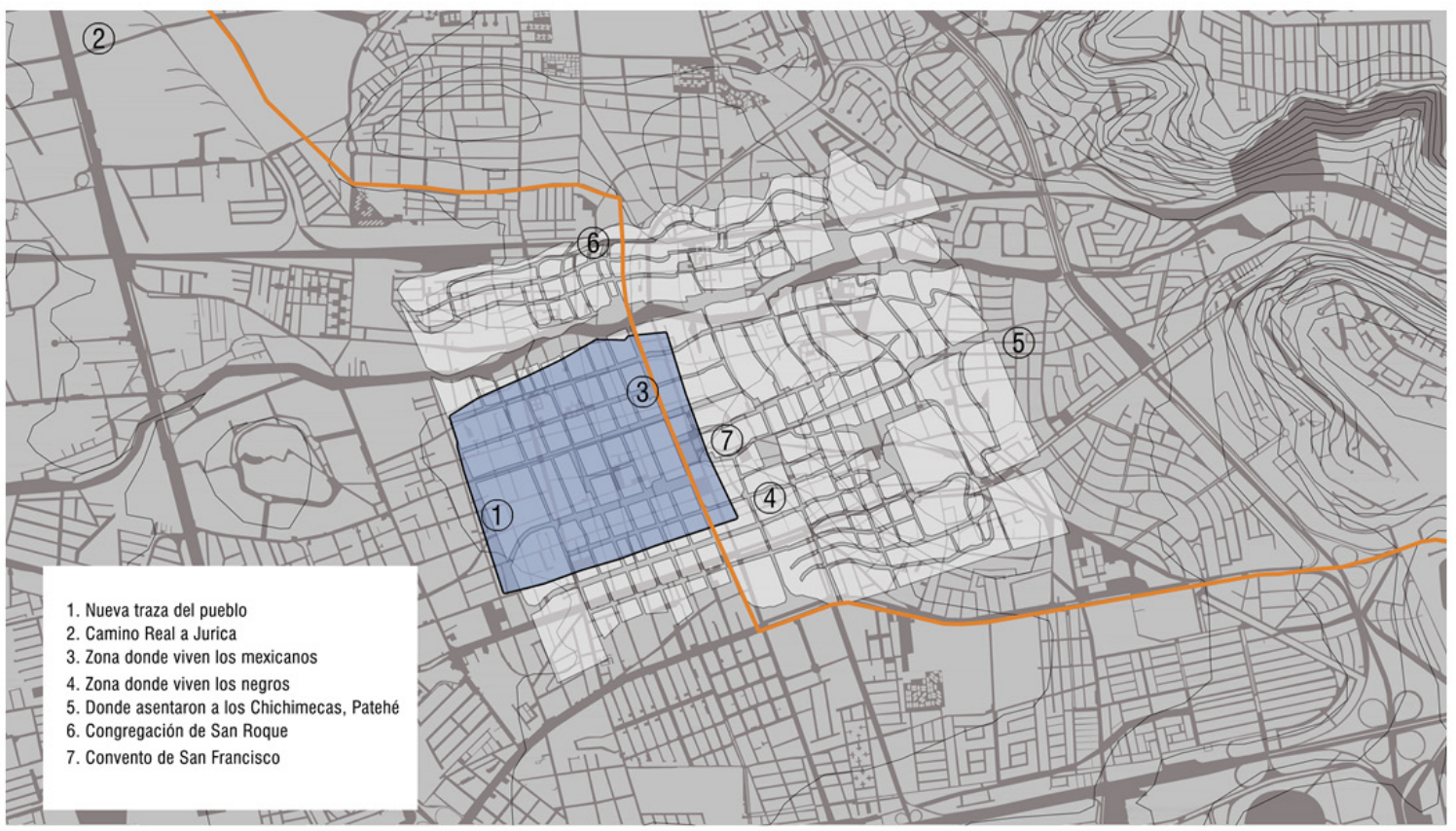

Asentamientos en la ciudad de Querétaro $0300 \mathrm{~m} \varnothing$

Fig. 1 (Mapa 1). Las Congregaciones de Querétaro 1602-1603. Por números: 1. San Roque, 2. La Cañada, 3. EI Rincón y 4. Santa María. Pintura presentada por Hernán Sánchez Cortés en 1620, quien era administrador del convento de Santa Clara. Fuente: Dos planos para Querétaro, Gobierno del Estado de Querétaro, Oficialía Mayor de Gobierno, Archivo Histórico, Provincia Franciscana de San Pedro y San Pablo de Michoacán, Querétaro, 1999. Fuente: recreado de Somohano (2006) y Arvízu (2005). Elaboración Propia (EP).

XIX, en 1810 los habitadores del Bajío y Querétaro emprendieron la revolución social de independencia del imperio español.

Carlos Arvízu (2005) enfatiza que en 1903 , la ciudad se ve fragmentada por la superposición de infraestructura de transporte al arribo del "Ferrocarril Nacional" a la ciudad afectando particularmente, la zona de estudio, tanto en su accesibilidad como en las relaciones socio-espaciales, las obras de infraestructura ferroviarias conllevaron para el entonces barrio de la Otra Banda la expropiación de amplias áreas de terreno y, en consecuencia "so pretexto de embellecimiento", la especulación de terrenos y fincas. Arribaron, nuevos habitadores entre obreros, empresarios oportunistas y comerciantes, se abrieron calles cercenando cortinas de árboles, dejando visible la hermosa nueva estación de ferrocarril, se instalaron de mesones, hoteles, bodegas y fondas. Se infiere la generación de "una segunda gentrificación" en la otra banda del rio.

El siguiente cambio intencionado de "desarrollo" por medio de la industrialización, ocurrió en el periodo gubernamental 19551961. En el "Mapa 2", se aprecia, lo que se conoce hoy día como los Barrios de la Otra banda, la vía férrea y, la nueva intervención realizada en la gestión gubernamental 19611967 misma que, resultó en la continuación de la avenida Corregidora iniciada en 1962 en dirección norte-sur, la sección del lado norte cercenó transversalmente parte de los barrios de la Otra Banda del río; se aprecia también la ubicación de lo que hoy es el mercado-tianguis "El Tepetate".

Para 1996, la declaratoria de Zona de Monumentos por la UNESCO, da empuje a la ciudad principalmente desde el punto de vista turístico, la declaratoria incluye solamente una parte de los barrios de la Otra Banda, ver "Mapa 3".

Mapa 3. Se muestran en colores los siete Barrios de la Otra Banda: San Gregorio, Santa Catarina, San Roque, El tepetate, El Cerrito, La trinidad y San Sebastián. En color amarillo la 


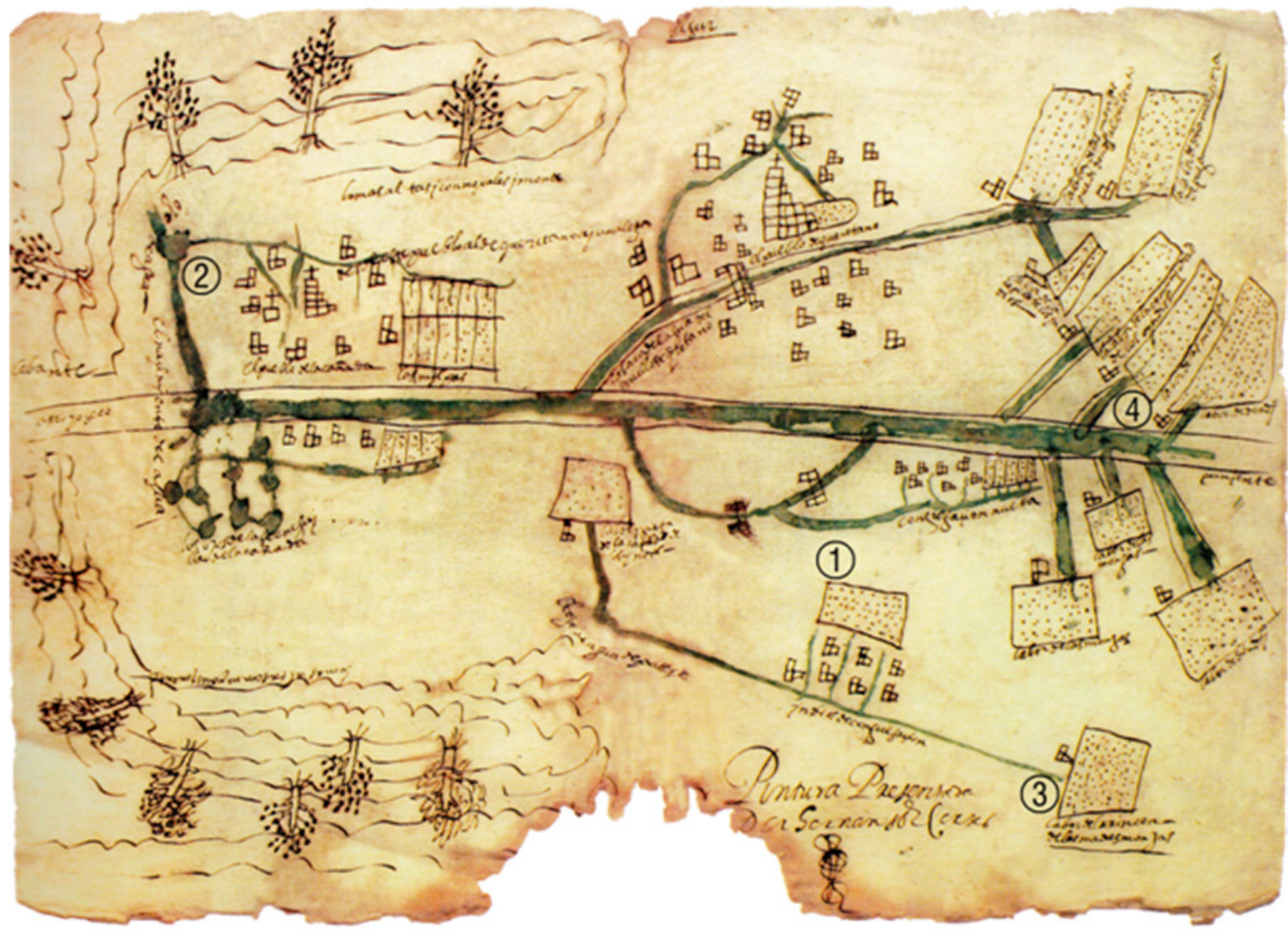

1. San Roque 3. El Rincón

2. La Caf́ada 4. Santa Maria

Congregaciones en la ciudad de Querétaro en 1602-1603

Fig. 2. Las Congregaciones de Querétaro 1602-1603. 1. San Roque, 2. La Cañada, 3. El Rincón y 4. Santa María. Pintura presentada por Hernán Sánchez Cortés en 1620, quien era administrador del convento de Santa Clara. Fuente: Dos planos para Querétaro, Gobierno del Estado de Querétaro, Oficialía Mayor de Gobierno, Archivo Histórico, Provincia Franciscana de San Pedro y San Pablo de Michoacán, Querétaro, 1999. Fuente: recreado de Somohano (2006) y Arvízu (2005), (EP).

Zona Patrimonio UNESCO, en verde su zona de amortiguamiento. En color rojo el mercado y tianguis El Tepetate. Fuente: Recreado desde IMPLAN, 2018, (EP).

Sirva este tímido acercamiento a historia del lugar como valor en la interpretación del presente que, si bien parece decantado hacia la forma urbana en apariencia solamente física, implica necesariamente, la consideración de la polisemia del término forma y su pluralidad de significados.

Querétaro continúa desarrollándose como una zona cuya vocación territorial, principalmente es la industria manufacturera. Continua por el camino de ofrecer la ciudad al inversionista, principalmente extranjero e, importando modelos de promoción urbana que no acaban de cuajar y que, estarían generando, nuevamente desde la visión de quien escribe, "una tercera gentrificación" en la ciudad.

\section{Del mercado "EI Tepetate"}

Oyón y Guàrdia (2010) plantean que, el mercado es un observatorio privilegiado de la ciudad, y éste es generador de impactos, pues tiene la capacidad de reestructurar el tejido social y comercial y, es justamente en éste tenor que se estudia el mercado "El Tepetate".

Aunque en sus inicios no puede encontrarse el mercado como espacio abierto, Lewis Mumford (2014) plantea que ello se debió a que, como espacio, el mercado era parte del recinto del templo (lugar en el que también se 


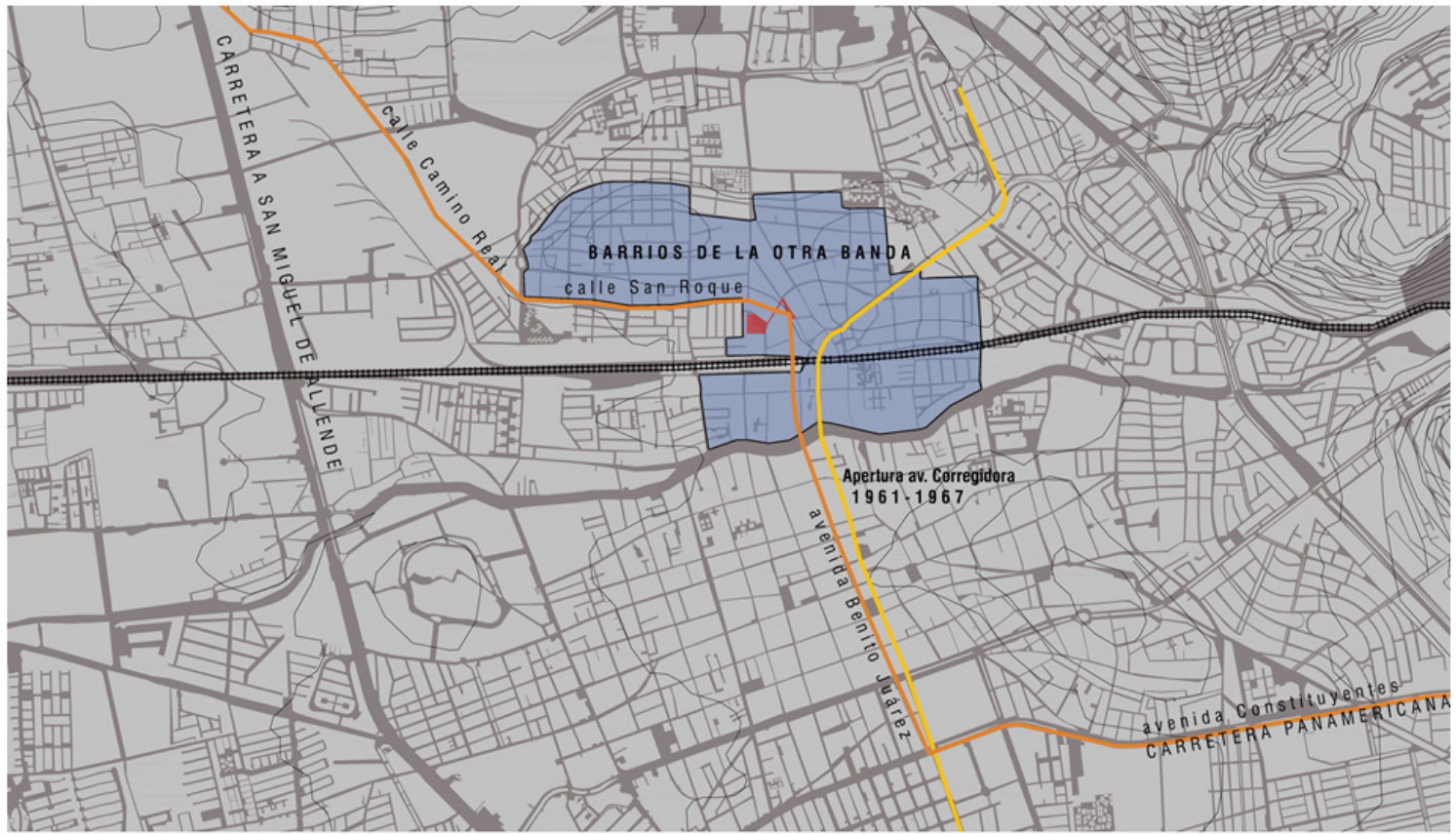

$$
\text { - Antiguo Camino Real }
$$

Apertura de vialidad paralela a avenida Juárez (avenida Corregidora) $0300 \mathrm{~m}$

Fig. 3 (Mapa 2). Se muestran en color azul los Barrios de la Otra Banda, la vía férrea, el Camino Real de Tierra Adentro, la apertura de la avenida Corregidora y en color rojo la ubicación del mercado y tianguis El Tepetate. Fuente: readaptado desde Arvízu (2005), (EP).

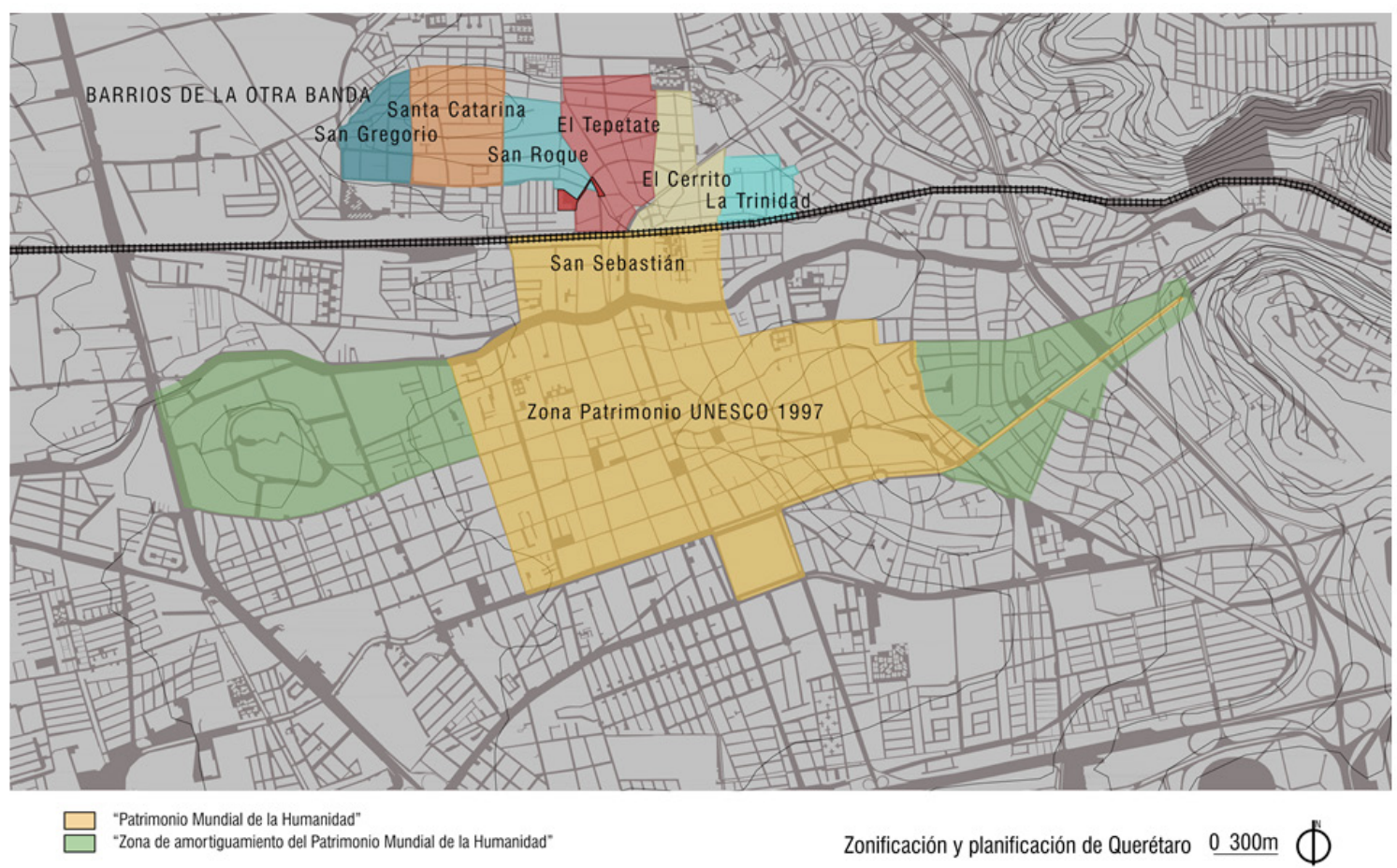

Fig. 4. (Mapa 3). Se muestran en colores los siete Barrios de la Otra Banda: San Gregorio, Santa Catarina, San Roque, El tepetate, El Cerrito, La trinidad y San Sebastián. En color amarillo la Zona Patrimonio UNESCO, en verde su zona de amortiguamiento. En color rojo el mercado y tianguis EI Tepetate. Fuente: Recreado desde IMPLAN, 2018, (EP). 


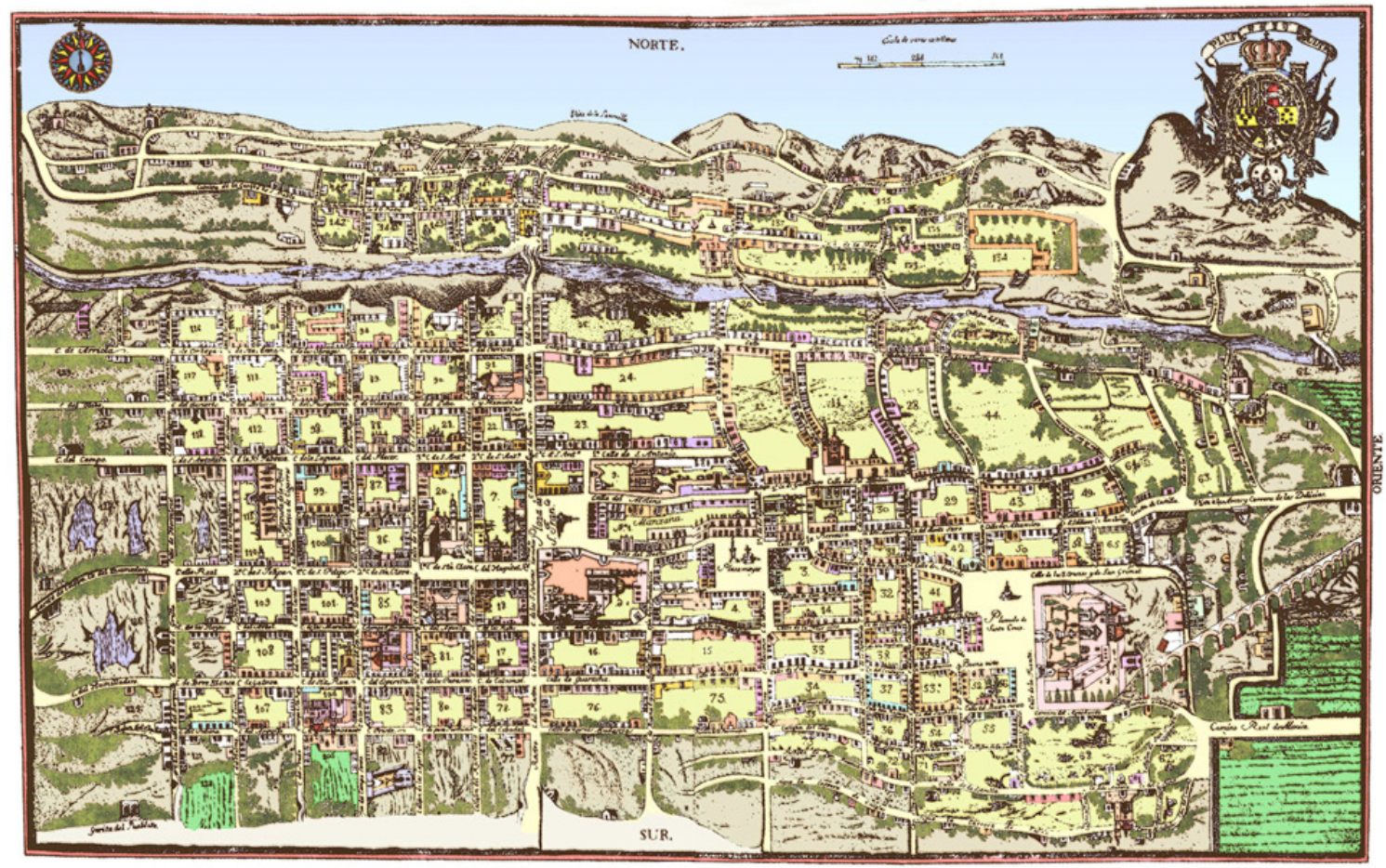

Fig. 5. (Mapa 4). Mapa histórico de 1796. Éste ya ha sido coloreado son algún software de ilustración cuando su color original, era sepia, sin embargo se usa debido a su calidad y mejor definición. Fuente: Centro Queretano de Recursos Naturales. CONCYTEQ (Concejo de Ciencia y Tecnología del Estado de Querétaro), 2017.

desarrollaban otras actividades), y que tiempo después, encontró ya un lugar en los sectores plebeyos de la ciudad. En las ciudades de las que se tienen registros de mayor antigüedad, las funciones del mercado - obtención, almacenaje y distribución|- se desempeñaban en el templo. La historia de los mercados en México (y en buena parte del mundo) ha sido poco estudiada, lo que ciertamente tiende a ser consensual es que han sido la fuerza modeladora de las ciudades (principalmente en Europa luego del Medioevo) y, en el caso de la cultura prehispánica del Valle de México también: "[...] Hay en esta Ciudad un mercado en que cuotidianamente, todos los días, hay en él de treinta mil ánimas vendiendo y comprando, sin otros muchos mercadillos que hay por la ciudad en partes". (Cortés-Gallangos,1866, pp. 68)

Se hace un paréntesis en lo correspondiente al mercado de la ciudad de la Edad Media dado que, se plantea una analogía de éste mercado para con el "tianguis mexicano".

Teniendo como referencia a Charles Delfante (2006): [...] Ya en la Alta Edad Media las ciudades cuentan con estructuras funcionales adaptadas a las exigencias de la economía urbana, que requieren en primer lugar plazas abiertas para los mercados, a las que las ciudades deben muchas veces su nacimiento $y$, la mayoría de las veces, su crecimiento. ( $p$. 101)

Las calles de la edad Media hacen las veces de mercado. Howard Saalman (citado en Delfante, 2006) refiere que, el resultado está a la vista: un tejido urbano de calles irregulares, que unen el centro con las puertas y siguen las prolongaciones lineales del mercado. La noción de red de tráfico brillaba totalmente por su ausencia como lo demuestra el incesante acarreo sobre ruedas. Las fachadas de las calles estaban recorridas por tiendas, especialmente en torno a las puertas. [...] La imagen de estas calles no debe, sin embargo, hacernos olvidar que los trazados dependian la mayoría de las veces de los sistemas de fortificación, [...] Ciertamente que las plazas de mercado constituyen la espina dorsal de las ciudades de la Alta Edad Media (p. 106).

El mercado "El Tepetate" ha sido y es, 
tres espacios simultáneamente: un mercado cerrado, el tianguis en sus calles aledañas y los locales fijos a los lados de dichas calles; lo escrito por Delfante, parece describir incluso este mercado: un tejido urbano de calles irregulares, la noción de red de tráfico brilla por su ausencia, las fachadas de las calles están recorridas por tiendas y ciertamente la plaza del mercado (El Tepetate), constituye la espina dorsal del barrio, de los Barrios de la Otra Banda.

No existe información respecto de si existía un mercado o tianguis antes de la denominada fundación de Querétaro en 1531. Jiménez (2011) refiere que el tianguis se celebraba frente al monasterio de la Orden Franciscana (centro de dominio político, económico y religioso), en la denominada Plaza de Abajo (p. 271). Se considera que la traza urbana indígena sirvió de eje para el trazo de la nueva ciudad y que el tianguis indígena se mantuvo a la llegada de los españoles. Aunque el esquema comercial de la tienda traída por los españoles, generó importantes transformaciones, el tianguis prevaleció.

El mercado tradicional al aire libre ha sido objeto de escrutinio ya desde el siglo XVIII a partir de la nueva percepción ilustrada del espacio público en Europa. En México, ideas similares han influenciado en no pocas veces a diversos gobiernos, no solamente en Querétaro. Cabe mencionar que "curiosamente", en tiempos recientes, se han incendiado varios mercados en el país, entre ellos, como ya se escribió el mercado El Tepetate mismo que, incluso luego del incendio, fue demolido en su totalidad y vuelto a "diseñar", reinaugurándolo en el pasado mes de marzo de 2019. Coincidiendo con David Harvey (2013) en lo que él denomina "destrucción creativa", viene ad hoc preguntarse si el día 10 de agosto de 2018 se haya marcado como fecha para dar el inicio hacia el cumplimiento del programa de redensificación se orienta hacia la revalorización del suelo en el mercado El Tepetate y que, a su vez, la renovación urbana de su entorno contribuya, por medio de la especulación, en aparente mecanismo hacia el freno de la expansión de la mancha urbana con el Sistema de Transferencia de Potencialidades para la Zona de Monumentos y Barrios
Tradicionales de la Ciudad de Santiago de Querétaro a fin de, obtener recursos para invertir en mantenimiento, cuidado y restauración de los edificios y espacios públicos de la Zona. Buen ejemplo del paradigma "Ciudad compacta versus ciudad difusa".

\section{Del método de análisis de la forma urbana.}

Para Amos Rapoport (2003) "no se puede estudiar construcciones aisladas, sino que hay que considerar la cuestión de cómo los edificios, formando parte de un sistema, se relacionan con los espacios abiertos, las calles, otros equipamientos, el paisaje circundante, las poblaciones vecinas o incluso las regiones colindantes [...], en muchas ocasiones es preciso estudiar los entornos de alto diseño junto a los ambientes vernaculares. [...] Es de gran ayuda para comprender los dos tipos de entorno, y con frecuencia ninguno de ellos puede ser entendido por sí solo, aislado del otro." (p. 26)

En la Otra Banda del río, la parte vernacular $\mathrm{y}$, del otro lado la ciudad colonial, con relaciones entre ellas, dos entornos como un sistema en donde, ninguno de ellos hubiera podido entenderse de manera aislada debido a la colonización. Así que, se estudian ambas bandas del río.

a) La forma urbana como herramienta interpretativa apoyada en la superposición de mapas históricos.

Mark Monmonier (1991) escribe que: "se considera de utilidad la flexibilidad de la cartografía como medio de comunicación al generar información nueva, y también, la oportunidad hacia el estudio de los males sociales" (p. 3). El resultado de la segregación territorial en la zona de la Otra Banda del río es susceptible de mostrarse mediante el empleo de la cartografía. Los mapas históricos son generadores de información cronotópica, ligan al tiempo con el espacio y a los tiempos entre sí, lo cual se complementaria con la visión muratoriana que, en cuanto a forma urbana, implica comprender que cada uno de los "estadios urbanos" sólo tiene sentido en relación a la forma urbana anterior y posterior (es cronotópico).

Se estudiaron varios mapas históricos, 
se presentan solamente dos de ellos. Se superpusieron los mapas antiguos sobre la traza actual de la ciudad de Querétaro, ello como una herramienta para la exploración, el descubrimiento y la comprobación de la hipótesis. Se presenta, de acuerdo a la técnica empleada por Saura (1997), un acercamiento a la organización tempo-espacial de manera gráfica de mapas de los años 1796 y 1844.

Se presenta la imagen del mapa histórico, en seguida, la integración y visualización ya como plano digital, sobre la traza urbana actual. Se hace una "limpieza" de mapas semi-artesanal, con software de ilustración; posteriormente, el mapa antiguo se acopla sobre la traza de la ciudad; deberá hacerse considerando la intención original del plano antiguo.

b) La forma urbana como herramienta interpretativa apoyada en la consideración de la teoría de Space Syntax y el software de análisis espacial multiplataforma DepthmapX. Bill Hillier (2007) plantea que al ser la arquitectura un arte social los edificios tienen fines sociales y por tanto, los entornos construidos parecen reflejar a la sociedad: "un edificio es una expresión de propósitos sociales, pero que no siempre es perceptible que, en cierto sentido, las formas son un producto del tiempo y el lugar" (p. 314).

El software de análisis espacial DepthmapX, presentaría los niveles de conectividad en la traza urbana en diferentes años para Querétaro. Los colores más fríos indican menor relación espacial y, los colores más cálidos indican mayor relación espacial, es decir, mayor accesibilidad.

Con los mapas históricos de 1796 y 1939 ya trabajados en superposición de mapas anteriores y, con la traza urbana actual de la ciudad de Querétaro se realiza el análisis espacial con Space Syntax Software buscando sus relaciones espaciales.

\section{De los resultados.}

a) En el "Mapa 4" se aprecia ya alguna traza parcelaria de la Otra Banda del río y escasas construcciones.

En el "Mapa 5", la traza en damero denota su diferencia para con las trazas urbanas dejadas a los naturales (parte derecha inferior y superior de la superposición).

En el "Mapas 6", ya se aprecia ya cierto "estilo" de representación. Áreas verdes en color verde y cuerpos de agua en color azul. Se aprecia luego la vía de ferrocarril, hacia el norte, mayor crecimiento en la mancha urbana hacia el noroeste de la otra banda del río.

En el "Mapa 7", la traza en damero denota su diferencia para con las trazas urbanas dejadas a los naturales (parte derecha inferior y superior de la superposición).

b) Para el "Mapa 8", el análisis muestra aceptable conectividad espacial en la traza en damero, a la derecha, colores cálidos corresponden a la explanada de la iglesia de la Santa Cruz. Color azul oscuro en la "Otra Banda" del río, se lee exclusión territorial luego las congregaciones de indios en 1603.

Para el "Mapa 9", el resultado del análisis espacial muestra aceptable conectividad en la traza en damero y hasta el Puente de los Héroes, pero luego de éste, la conectividad espacial es escasa en la traza urbana. Segregación territorial manifiesta el color azul oscuro en la Otra Banda del río.

\section{Conclusión}

Es claro que la consideración de tiempo y lugar, se encuentran en profunda relación, ello contribuye a dilucidar que, la profundidad de la forma urbana está en constante diálogo sobre el territorio de la Otra Banda. El análisis de la forma urbana en diversos tiempos, está manifestando un carácter relacional que, es generado de diversas formas urbanas precedentes, así mismo, es agente de otras formas urbanas que estarían por venir; en esa relación existe un profundo diálogo en el tiempo y en el territorio de ubicación del mercado El Tepetate.

Las dos herramientas interpretativas de la forma urbana, contribuyen a mostrar desde un punto de vista morfológico que la segregación territorial pervive desde 1602. Debe promoverse la conectividad física entre los Barrios de la Otra Banda y la ciudad histórica. La segregación territorial y en consecuencia la exclusión social en la zona continúa presente. 


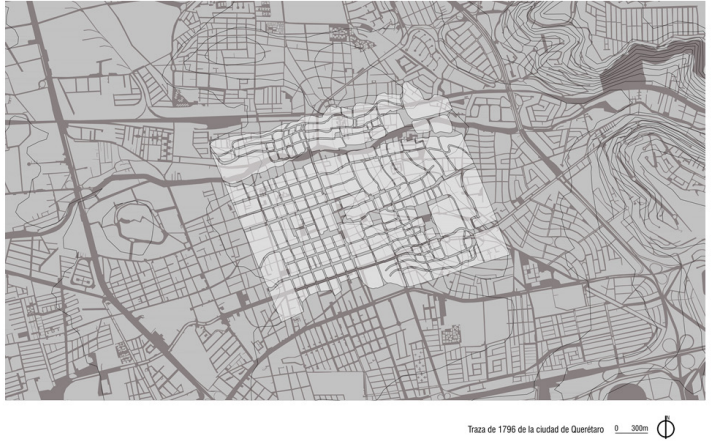

Fig. 6. (Mapa 5). Superposición de mapa histórico de 1796 en traza urbana actual. (EP)

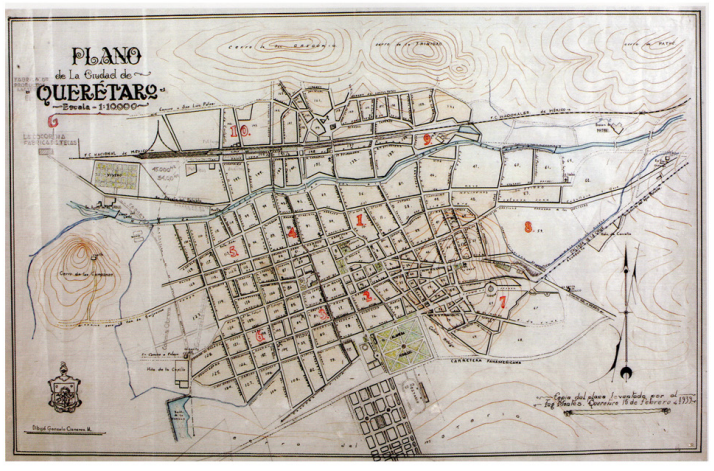

Fig. 7. (Mapa 6). Mapa histórico de 1939.

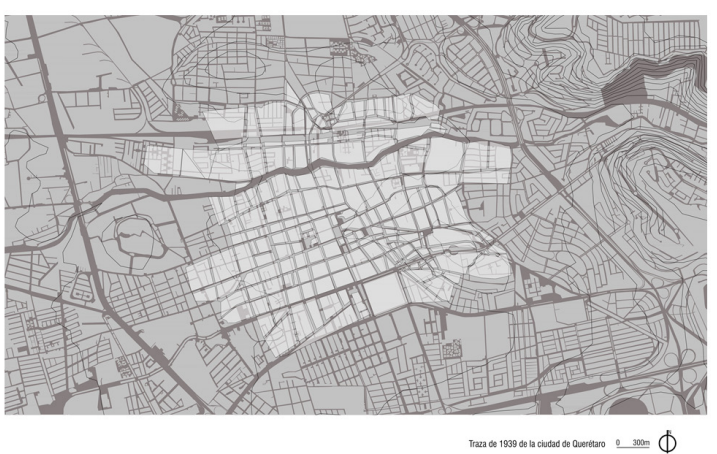

Fig. 8. (Mapa 7). Superposición de mapa histórico de 1939, en traza urbana actual. (EP)

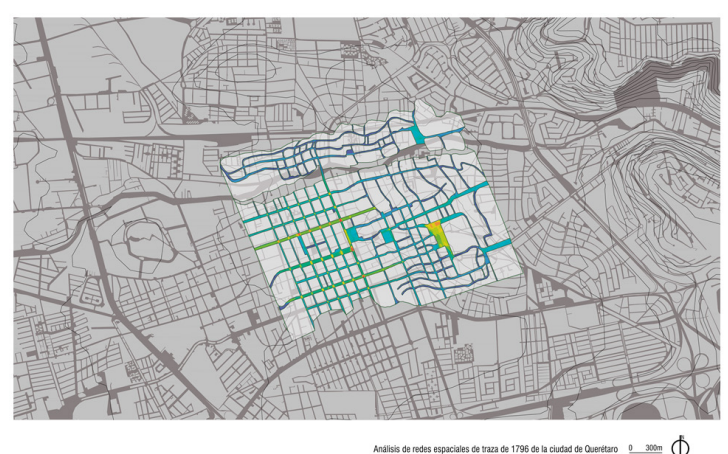

Fig. 9. (Mapa 8). Análisis de la sintaxis espacial en mapa de Querétaro de 1796. (EP)

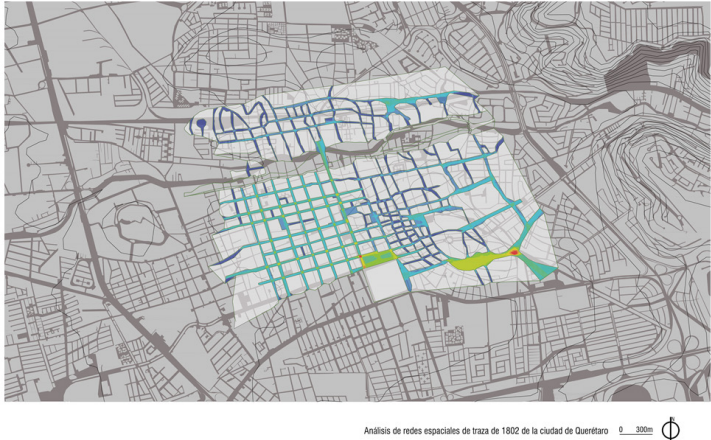

Fig. 10. (Mapa 9). Análisis de la sintaxis espacial en mapa de Querétaro de 1939.

\section{Agradecimientos}

Al Tecnológico Nacional de México.

\section{Notas}

1 En México, la palabra Tianguis refiere al mercado abierto público, deriva de la lengua Náhuatl "tianquiztli"

2 El concepto "cronotopo" ha sido establecido por el teórico de la literatura Mijaíl Bakjtin para referirse a las formas en que las novelas relatan el tiempo y el espacio, creando escenarios dialógicos en los que, los sujetos interactúan de una manera particular (Muntañola, 2007). Muntañola, hace una aproximación al paradigma de Bakjtin tendiendo puentes entre dialogía y arquitectura.

3 En México, la palabra Tianguis refiere al mercado abierto público, deriva de la lengua Náhuatl "tianquiztli"

4 Gerhard (2016) utiliza como sinónimos las palabras congregación, reducción o junta.

\section{Referencias}

Arvízu, Carlos. 2005. Evolución urbana de Querétaro: 1531-2005. Querétaro. ITESM/ Gobierno de Querétaro.

Choay, Françoise. 2007. Alegoría del patrimonio. Barcelona: Gustavo Gili.

Cortés, Hernán-Gallangos, de Pascual. Cartas y Relaciones de Hernán Cortés al Emperador Carlos V. Obtenido de Biblioteca del Patronato de la Alhambra y Generalife: http://hdl.handle.net/10514/6072 (1866, París. Imprenta Central de los Ferro-carriles. 
A. Chaix y C.).

Delfante, Charles. 2006. Gran historia de la ciudad. De Mesopotamia a Estados Unidos. Madrid: Abada Editores.

Harvey, David. 2017. Ciudades rebeldes, del derecho a la ciudad a la revolución urbana. España: Akal.

Hillier, Bill. 2007. Space is the machine. A configurational theory of architecture. Electronic Edition: Space Syntax.

Monmonier, Mark. 1991. How to Lie with Maps. Chicago. University of Chicago Press Mumford, Lewis. 2014. La ciudad en la historia.Sus orígenes, transformaciones y perspectivas. España: Pepitas de calabaza.

Oyón, José-Guàrdia, Manuel. 2010. Hacer ciudad a través de los mercados. Euopa, siglos XIX y XX. Barcelona: MUHBA.

Rapoport, Amos. 2003. Cultura, arquitectura y diseño. Barcelona: Edicions UPC.

Saura, Magdalena. 1997. Pobles catalans. Barcelona: UPC.

Gerhard, Peter. 2016. Congregaciones de indios en la Nueva España antes de 1570. Historia Mexicana, El Colegio de México, vol. 68, núm. 1 (269), 347-395.

Jiménez, G. J. (2011). El Camino Real de Tierra Adentro a su paso por el pueblo de Querétaro y el mercado a finales del siglo XVI y principios del XVII. Históricas digital, 261-290 http://www.historicas. unam.mx/publicaciones/publicadigital/ libros/caminosymercados/mercados.html.

Somohano, Lourdes. 2006. La movilidad poblacional en Tlachco/Querétaro, siglos XVI y principios del XVII. Redalyc. Sistema de Información Científica. Papeles de Población, 12 (49), 239-262. 